\title{
Society in need of transformation. Citizen-Foresight as a method to co-create urban future
}

\section{Doris Wilhelmer}

Abstract: The European Commission highlights that creating shared values and democratic citizenship is a today's requirement to answer challenges of urbanization in Europe. The awareness about the necessity of inclusion of vulnerable groups such as elderly or migrants is still a substantial deficit in research on inclusion.

As a matter of principle, future cannot be forecasted. The most effective way to foresee future is to jointly shape it! The Participatory Citizen-Foresight offers a neutral transformation-room and multi-method coordination-framework for detecting accessible and tacit-knowledge for change. In co-creation citizens, experts and Civil-Servants gain insights into complex interdependencies allowing mutual learning and behavior in rehearsal for transition. Society is in need of powerful, collective pictures serving self-confidence and self-responsibility of citizens.

First, we describe the specific, participatory-foresight approach. Second, we highlight preconditions for learning and societal change based on constructivism and brain research. Third, we show how this can work in reality by shortly outlining two Citizen-Foresight cases with elderlies and, fourth, we derive selection-criteria for methods aiming at transforming mental images, maps and behaviour.

Keywords: demographic change, participatory-foresight, citizen-foresight, societal-change

\footnotetext{
* Austrian Institute of Technology (Austria) doris.wilhelmer@ait.ac.at
} 


\section{Introduction}

\subsection{Initial situation}

Today we face economic crises and global challenges driving societal and political transformation in Europe. The European Horizon-2020 strategy was developed to address major concerns shared by citizens in Europe and aiming at solving key global health and development problems by agenda setting of policy-priorities. The issues covered are grand in scope and scale, and are generally made up of "wicked problems" (Rittel \& Weber, 1973) that are even impossible to solve by single agencies or through rational planning approaches.

\subsection{Society in need of transformation}

Transformation is a systemic phenomenon by nature resulting from continuing interaction between different actors and organizations (Freeman, 1970). This means that an organization does not change in isolation but rather in interaction with its environment. Such environments are complex by nature and difficult, indeed, mostly impossible to shape with a view to directing transformation in a predictable topdown manner. This highlights the fact that a one-size-fitsall approach to promoting transformation is unlikely to work across the range of challenges to be addressed.

Context-sensitive approaches aiming at sustainable transformation have to activate various resources. For successfully doing so, a) facilitation of experimentation and learning as safeguarding "variety", b) nurturing knowledgedevelopment besides science and technology, and c) knowledge-diffusion are needed (Cagnin et al., 2012).

\section{Need of future-oriented scicted learning}

Grand challenges draw attention to long-term trends and risks. Today's decision-making should not only focus on current questions but also has to cope with upcoming opportunities and threats.

With increasing numbers of governmental but also nongovernmental organizations taking part in a future-oriented- 
governance, the coordination of diverse sets of organizations becomes more important. A large number of measures have been tried for enhancing government-coordination (Peters, 1998; 2001; Verhoest et al., 2007; Lindner, 2012; Biegelbauer, 2013; Laegreid et al., 2015) for the policy and administrative levels on the one hand and citizens on the other.

Foresight processes offer a future-oriented framework to assist policy-makers as well as business and societal actors in managing the uncertainty of future developments by providing spaces to come together, to better appreciate their mutual positions vis-á-vis various solutions. Oriented on grand-challenges, new knowledge as well as a new type of learning in the sense of so called "mode 2" knowledge-production (Nowotny et al., 2003) is needed.

In the following we want to show that the future-oriented approach of Participatory-Foresight is a new instrument of coordination aiming at both policy and societal learning.

\section{Participatory-foresight as an instrument of governmental-coordination}

\section{What i f foresight?}

Foresight is a conceptual-framework as well as a process of prospective analysis and informed decision-making that includes long- to mid-term considerations of likely, possible, or even just thinkable futures (Miles, 2008). Aiming at context-governance backwards from future-perspective foresight-outcomes are expected to deserve the label of sustainability and innovation. This requires complex processes of transformation demanding the combination of foresight methodology with principles and techniques stemming from organizational development (Wilhelmer \& Nagel, 2013).

\section{L2. Participatory-foresight - future emerges in co-creation}

Due to the demand to answer upcoming grand challenges, we can detect an increasing need for forward-looking approaches in policy and economy. 
Foresight allows:

1. the acceleration of change in science and society offering foresight expertise beyond short-term horizons;

2 . the increase of interdependencies and interlinked networks by widening classic planning limits;

3. the limitation of room-of-maneuver of individual keyactors by carrying out coordinated action in the meaning of process and result:

4. answering to the demand for concerted orientation and visions by integrating diverse perspectives, disciplines as well as implementation of results while mobilizing stakeholders trough participation.

Social systems depend on their capability of collective sense-making processes. Organizations, projects and networks are obstructed in elaborating good results if their members start to struggle with each other. Reality becomes what gains an impact and that is why the intense communication within Foresight processes can influence the transformation of social systems. This demands opening options for exploiting given collective knowledge-repertoires of experts, civil society as well as decision-makers concerned. Nobody can drop out from his or her experiences, roles and context: dialogue-based Participatory-Foresight processes pick up and combine all these divers perspectives based on reliance, curiosity and appreciation for reliable and jointly assessable, future-oriented solutions.

The pioneer of European peace-movement Robert Jungk is said to be the inventor of Participatory-Foresight processes in the Eighties inviting ordinary people to discuss with experts of economy, science and policy. Thereby he aimed at enabling communities and networks to take the role of a counterweight to civil servants and politics.

Although we cannot know what will happen we shape with today's actions our future and create pictures of our world of tomorrow. The option to look back from a desirable future to the present allows building backwards-scenarios framing future-oriented roadmaps and action-plans. Thereby, Foresight processes are able to mobilize huge energy for implementation by means of motivating key players of different sectors. 
One huge benefit of Participatory-Foresight is that with only little efforts radical changes of mental models and patterns-of-behavior can come to reality. The chance that stakeholders have transformed their mind-sets and routines afterwards is rather high.

Thus, foresight is implemented as an instrument of social context-governance by realizing a hybrid set-up for strategic reflection thus changing old debates by means of a wide participation.

\section{Foresight phases and method-mix}

Foresight processes on a timeline pass of three phases:

The Pre-Foresight - goals, orientation, the scope of timehorizon, stakeholders.

The Main-Foresight - environmental analysis of drivers $\&$ megatrends, emerging issues, scenarios \& visions.

The Post-Foresight - strategies \& policy recommendations, networks for decision, evaluation (Miles, 2008; Popper, 2008).

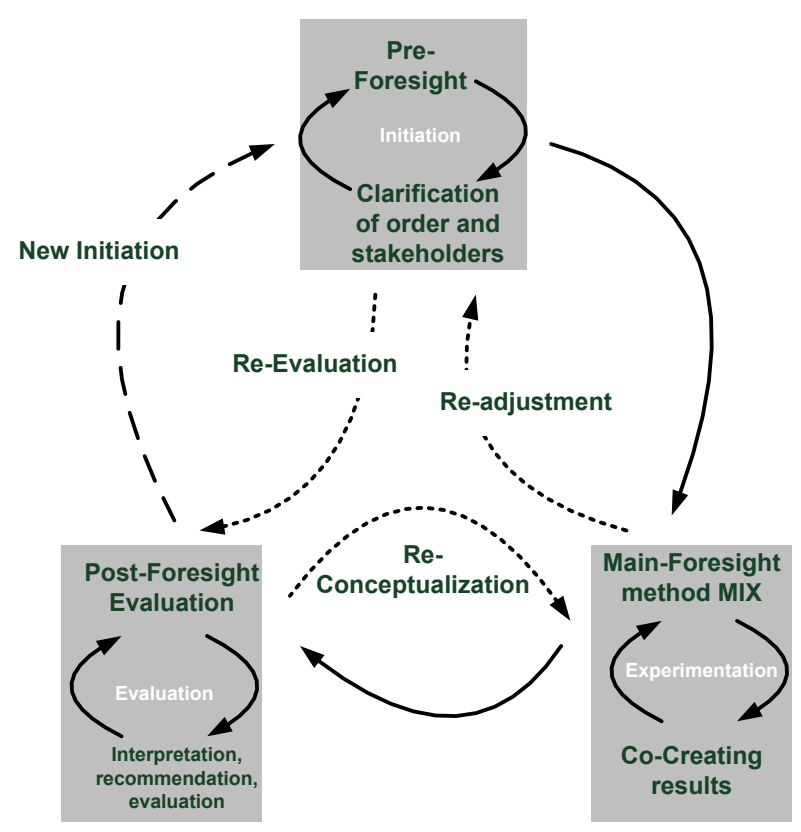

Figure 1: Circular Foresight Process

(Wilhelmer \& Nagel, 2013, p. 27). 
In order to support decision-makers in setting-up foresight processes Wilhelmer and Nagel (2013) assigned foresight methodologies according to these three phases. Following Popper (2008), one may group all methods into four categories. Foresight methods aim at:

1. collection and interpretation of expertise available, e.g. expert-panels, interviews, scenario-building, roadmapping, etc.,

2. extrapolation of evidence-based knowledge from publications, patents, market/trend analysis, modelling, bibliometric searches, etc.,

3. interaction by means of Future Conferences, OpenSpace, World-Café, citizen-panels, etc.

4. co-creation and creativity by means of wild cards, improvisation, play-back theatre, role-play, sciencefictioning, graphic facilitation, etc.

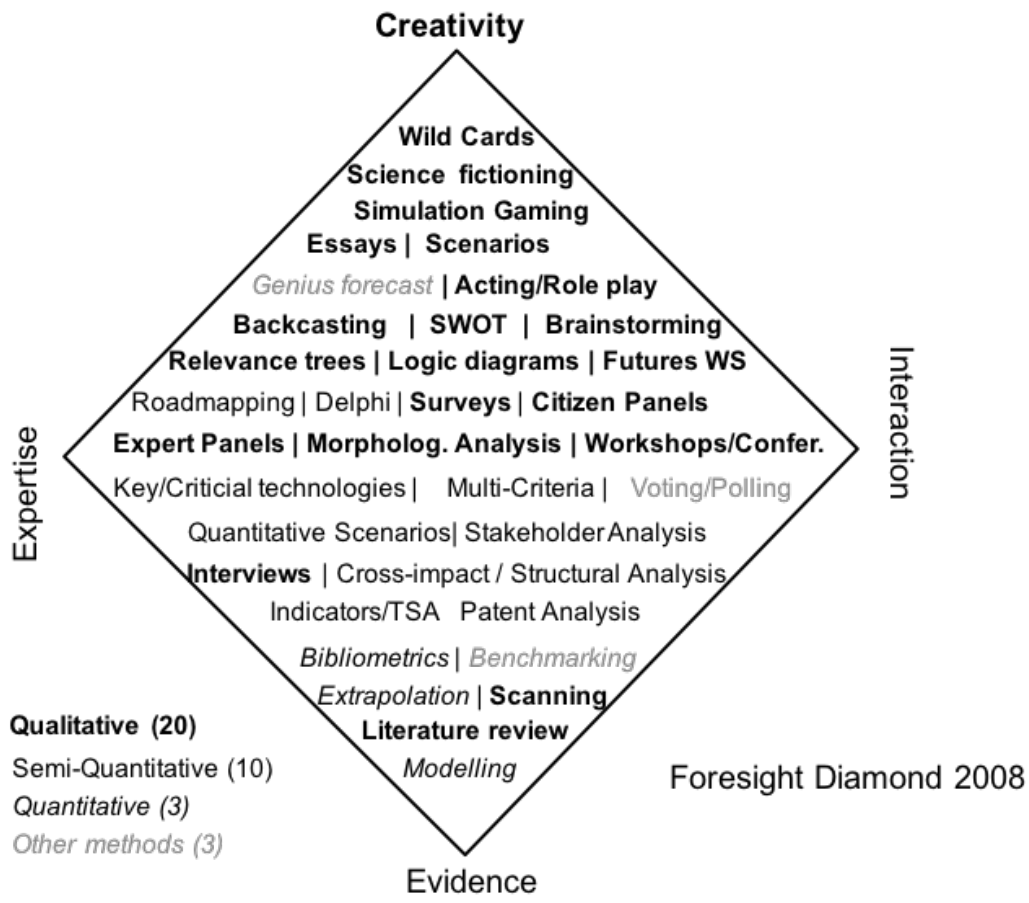

Figure 2: Popper's diamond (Popper et al., 2008).

Citizen-Foresights demand a suitable combination of these categories aiming at pacing citizens in their 
mental models as well as leading them into new dimensions of observing and interpreting their environmentalcontext.

\subsection{Social foresight architectures}

Participatory-Foresight processes combine both logic and structural elements of project management as well as of (trans-)organizational development. In this regard, a coreteam and steering-board, an advisory-board and a stakeholder-forum, including 60 to 250 people, are essential for governing Citizen-Foresights.

The core-team is coordinated by a foresight process-owner, conceptualizing and facilitating the overall foresight process. Both the process-owner and the core-team serve as the heart and engine for conducting co-creation processes.

Members of the large stakeholder-forum assume responsibility for shaping process and results by contributing their personal experiences and expertise. Another key-mission is to reflect intermediate results with confidantes of "homeorganizations" thus spreading and adapting foresight results to environmental requirements.

The strategic-steering-board is the third element: it flanks the overall process, thereby involving clients to an unusually high extent. This allows for controversial discussions and mutual learning processes of clients as well as foresight core-teams.

The supplementary advisory-board brings together civil servants with researchers from universities and applied research in regular evaluation meetings.

These elements of context-governance aim at offering a suitable communication framework for enhancing the unfolding of trust, reliability and self-responsibility as well as the emergence of novel knowledge. Three set-ups of context-governance are bundling these structural elements aiming at a) process-governance, b) search for new information and c) transformation of mental landscapes and patterns of the stakeholder-forum as a system as well as individual members concerned:

a) A governance set-up (project-manager, core-team; steering-board, advisory-board in charge of conceptualizing 
the process design and conducting/ adapting the foresight-process).

b) A development set-up (project-members; responsible for searches, patent analysis, modelling, etc.).

c) A transformation set-up (stakeholder-forum responsible for contributing experiences, plausibility checks, assessments, etc.).

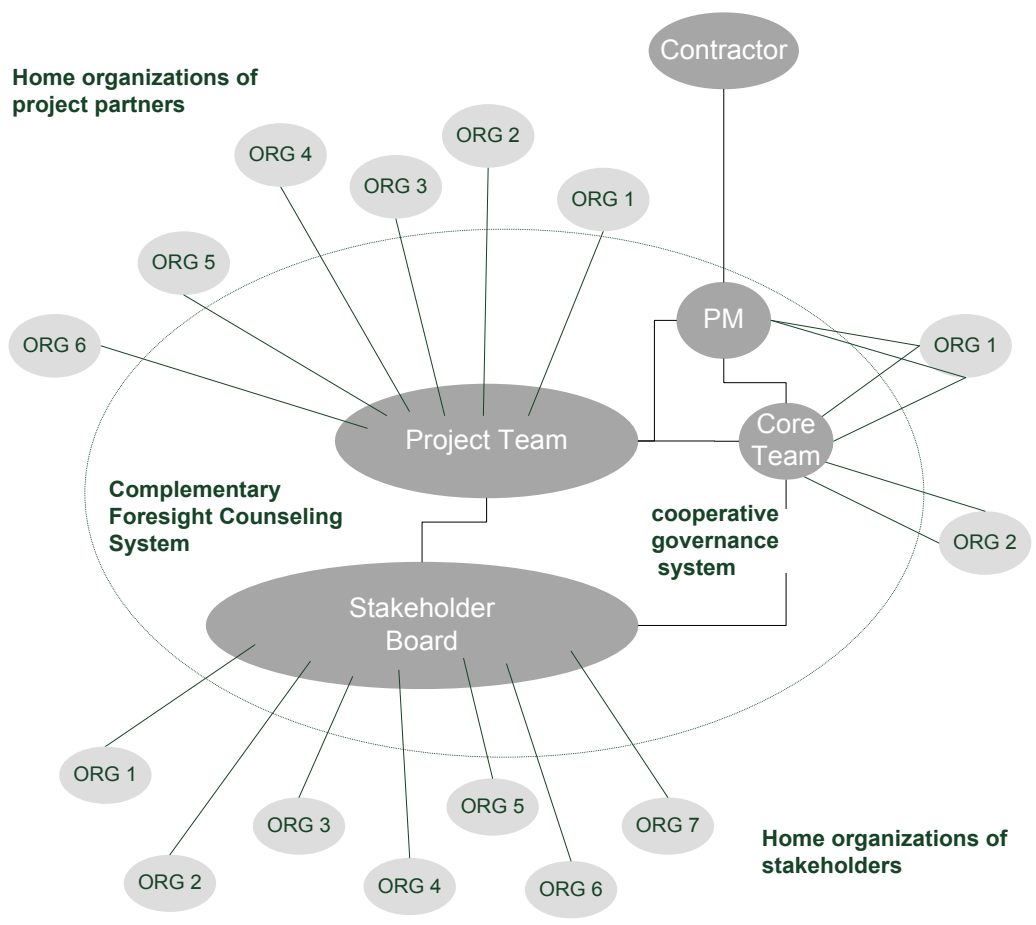

Figure 3: Social foresight architecture

(Wilhelmer \& Nagel, 2013).

\section{Precondititions for learning and sccietal change}

\subsection{Context governance approcch allowing ssstem learning}

Willke (2004) points out that social systems are able to learn faster and more efficient than their competitors if they learn how to learn and if they decide on a strategic level, what should be learned preferentially. Thereby the instrument of large group processes and the collective wisdom of all stakeholders show up to be critical for engaging different 
voices, balancing interests and for making connections and coordinating experiments of novel thinking and acting (Cagnin et al., 2008). Especially feedback-loops between stakeholders encourage mutual learning processes.

This context-governance approach allows policies related to networks and community-building aiming at visioning, experimenting, mutual learning and co-creating as multidimensional multi-actor processes. This form of accountable governance is better able to jointly anticipate and adapt to future, addressing common challenges and spreading democracy at a global level (Boden et al., 2010). Finally, this approach allows transcending boundaries to better utilize multiple levers for shaping societal-change. Context-governance as a coordination-effort enhances communication and understanding between policy-silos thus supporting transformation (Cagnin et al., 2012).

\section{3.. Parandolo of how to decide under uncertain cirumstances}

Modern social systems are characterized by a complexity, overburdening actors from policy, economy and science. Today's decision-makers face the challenge to align their organizations to a future and in parallel to accept, that future as a principle is neither foreseeable nor projectable. Decision-makers have to continuously deal with this constitutive paradox of the future in a smart way.

Solutions can only offer temporary optima for specific contexts. This provides continuous energy to revisit decisionmaking for complex challenges.

Dealing with uncertainty is in need of clear cornerstones to allow navigation. Clear scopes of governance set-ups and a high variety of instruments are needed for guiding strategic discourses in organizations and policy.

Following constructivist principles, foresight is seen as a communication process allowing future-oriented decisions in the present for the present. Methods thereby have to balance both the necessity and impossibility of future planning. Results not aiming at integrating both quickly are passed by reality.

A specific method-mix aims at allowing all stakeholders to better understand unexpected future developments. Thus 
co-creating futures offers a collective rehearsal for transformation in the present (Wilhelmer, 2013).

\section{Asking instead of telling}

A user-centered approach in policy coordination requires resigning from familiar expert-talks. This demands getting beyond expert-driven competition with respect to "truth" and "relevance". Researchers as well as experts from public authorities, NGOs and industry have to change from "telling" to "asking" and from "claiming" to "mutual learning". This demands an investment of more time than usual in clarification processes.

\subsection{Transsormation in need of neltral OD-Counselors}

Societal transformation requires a context-tailored combination of both content point-of-view and mediation/socialprocess (Wilhelmer, 2009).

The organizational development (OD) allows to build an appreciative cooperation culture as well as to tailor a contextsensitive, multi-method approach by means of applying creative, interactive methods and analytical methods feeding in outside-perspectives.

OD initiates meta-reflection and self-organization of the project team supporting its navigation through contradictory logics and power struggles.

\section{Tomorrow-Todaly}

For shaping future-oriented processes of societal learning, one should take into account how humans can deal with past, present and future. Humans only can live in present as a principle (Schmidt, 2004). Only story-telling makes glimpses of yesteryears and possible futures accessible. Thus, past and future can be seen as construct of communication: observers in specific contexts following unique motivation construct stories. Sharing these stories allows also sharing appropriate rationales affecting our actions in daily-life. Modern brain-research points out that our biographical memory derives from combinations of faulty mementos (Markowitsch, 2013) and humans experience negative 
stories on physical level. The body experiences a verbal threat of violence as a real happening injury (Schmidt, 2004). This makes story-telling such a powerful instrument aiming at transformation of mental models.

Milton Erickson (1954) calls the human's capability to go for journeys through time "pseudo-orientation in time" or "time-progression". This allows to experience of desirable future as present on an emotional and physical level. The flow and power inherent to the anticipated future delivers energy to change dysfunctional routines of thinking and acting.

\subsection{Crises demand powerfill, ollective images}

New knowledge often does not fit to traditional views of the world. Old ideas embedded in collective memories of clans, tribes and ethnic groups have to be adapted to new circumstances.

Humans, organizations and societies organize themselves by means of mental images like myths, legends, religions, etc. These stories enhance the cohesion of social systems by indicating desirable regimes. Brain research (Hüther, 2010) tells that collective images can give urgent orientation in times of disruptive cracks and the necessity of reshaping our living environments. Confidence and reliance drive social transformation processes.

Following Helmut Willke (1998), developing a joint desirable vision does not aim at obedience or behavioral change by group pressure. On the contrary, the insight that humans unfold surprising potentials when focusing on true visions works as a guiding principle for foresight processes: people learn on their own motivation beyond pressure and instructions.

Following this logic, vision-building cannot be conducted top-down but only can be co-created in a joint bottom-up process (Wilhelmer, 2013).

\section{Change is what happens before results are fed into implementation}

Long before formal results are implemented stakeholders already have changed their thinking and acting: change is what happens before official decision-making. 
Within "cultural-islands" (Schein, 2010), ParticipatoryForesight initiates mutual learning processes. Cultural-islands open incubation rooms for generating new patterns of thinking and acting. Stakeholders oscillate between the two worlds of "daily routine" and "incubation room" thereby deepening insights and learning in practice. Participatory-Foresight allows the rehearsal-for-transition within protected transformation spaces. Additionally, collective assessments of appropriate findings drive transformationprocesses inside out thereby changing cultures and values of social systems. Finally, but most importantly, this approach increases the legitimation of policy-design outcomes and R\&D-policy generated within the framework of a representative democracy.

\subsection{Sustainability in need of a combined top-down and bottom-up approach}

Sustainable impacts of foresight demand co-creation by a high variety of stakeholders concerned. This serves as precondition for effective policy and societal learning. No Foresight process can take place without a client. Successful policy coordination amongst other things needs an organizational-framework such as RTI-strategies on European and national level. Funding supporting-activities is very helpful. For the coordination in general, but especially for participatory activities the presence of urban and ministerial decision-makers is of utmost importance.

Foresight processes mark a social and political antithesis to short-term thinking and the habit to stick to one's own interests. There is a need to utilize tacit knowledge and innovative ideas for society referring to social innovation "by its ends and needs" (Wilhelmer, 2013). From a democracy-policy perspective, aiming at wellfare policy and societal change there is a need of inclusion of a wide range of people.

\subsection{We are the change}

Nowadays stakeholders have an important role in view of finding adequate answers to grand challenges in democratic manner. The entrepreneur and pioneer Paul Hawken points out an increasing role of non-profit organizations since 
the Nineties: counting international non-profit-organizations Hawken indicates an increase from 40 organizations in 1948 to 700 organizations in 1992 without counting NPOs on national level. This development marks a great social movement and his hypothesis is that it reacts to the increasing awareness of urgent threats deriving from climate change and limited natural resources of our planet (Senge et al., 2011).

\subsection{Governing social systems from a long-term future perspective}

Scenario-building addressing a long time ahead unfolds novel spaces for creativity. Most people imagine themselves to be $80+$ years old, facing radically changed environments and physical conditions or anticipating their individual death. This widens the perspective on the evolution of generations, societies and of our planet as a whole. While mind becomes free on the mental stage, fantasy and engagement emerge. In magic moments like this, we can perceive reality in an unbiased and unprejudiced way as if a curtain would be drawn aside. Governing from a future-perspective opens free space to identify a high variety of levers aiming at transformation.

\section{Challenges of two Citizen-Foresight cases}

In the following we will describe two AAL Citizen-Foresight processes in Austria, one taking place in an urban and the other in a rural area. The overall goal of both Citizen-Foresights was to lift current and future demands for activeassisted-living technologies for elderlies.

\subsection{Cases study WEGE-2015}

Starting with the rural area, we saw ten, small, neighboring municipalities of Mühlviertel, acting as client and user. This area suffers from missing economic and educational infrastructure. As income only derives from agriculture and crafts, most young people already left for studies and jobs to nearby cities. Thus, mostly elderlies live in one-family houses in the midst of a beautiful countryside suffering 
from immobility, isolation and helplessness when losing their partners by reason of death. As the number of physicians is shrinking, there is an increasing risk of health threat for aged people. In order to go against migration and shrinking public budgets ten mayors started coordinated actions about twelve years ago addressing the inclusion of young people, migrants and elderlies. They aim at extending their poor ICT and mobility infrastructure, which is seen as utmost source for future prosperity of the region. Thus, mayors require formal results based on hardfacts, legitimating claiming for more federal engagement. Regarding the Citizen-Foresight WEGE-2025 case, besides 50 to 60 voluntarily stakeholders, about half of the mayors continuously joined the mutual learning-processes. The other $50 \%$ kept in distance only visiting regularly steering-board sessions. As an external project partner claimed the mayors' coaching to be exclusively his responsibility, balancing both interests of mayors and citizens turned out to be a tough challenge for the project-manager and process-owner.

On the one hand, half of the mayors and about 50 citizens jointly developed an implementation-project including mobility, medical services and regional health-care-coordination. On the other hand, the five mayors and their project coach came independently up with the plan to submit a dissemination-APP in order to push the extension of the regional ICT-infrastructure. From a systemic perspective, WEGE-2025 was very successful: citizens and mayors supported the submission of the dissemination-APP based on the new awareness that the upcoming ICT-revolution will change all areas of life. Additionally, citizens started transforming one-family houses into shared housing projects thus continuing cooperating on an informal level. Besides, the local project manager was offered an executive-function of the largest assisted accommodation for elderlies.

Challenges for the research-team were to a) carefully build on results of already existing initiatives, b) meet the need of citizens to articulate their problems and jointly build on solutions in an inspiring and joyful atmosphere. Additionally, the team had to meet the requirements c) of five 
mayors interested in the needs and wants of their citizens and enjoying to deepen relationship within dialogues and d) of another five mayor to quickly receive results for successfully negotiating with federal ministries. Besides, the Citizen-Foresight had to e) allow both mutual-learning as well as formal foresight results and to f) enhance decision-making for a follow-up demonstration project.

\section{L. Casestudy SAll-Vienna-2035}

Well-educated and successful founders of the self-organized residential house Sargfabrik (100 flats) are facing their upcoming retirement. Used to self-responsibly shaping their mode of housing, working and influencing Austrian policy regarding climate-change, green mobility etc. the founders decided to self-responsibly prepare a supportive environment for their $3^{\text {rd }}$ and $4^{\text {th }}$ phase of life. An additional property was bought and a Citizen-Foresight was submitted in order to support conceptualization and implementation of an innovative care-service for the residential house and its neighboring district. The Austrian funding-agency FFG decided for funding, as self-organized residential housingassociations are seen as social-innovation, able to increase the variety of aging-cultures and the life-quality of all urban generations.

The now ongoing Citizen-Foresight includes about 50 voluntary stakeholders, the majority originating from Sargfabrik restocked by a few members of three additional residential houses and several citizens from a neighboring-district. Besides, an important Viennese care-organization and representatives of companies, the municipality and infrastructure-ministry join the future-workshops.

The local project management at the same time holds a function in the Sargfabrik management-board. For Sargfabrik she has to guarantee an entertaining process and a project result supporting the build-up of the care-services. Immediate feedback of management-board-members and inhabitants to single foresight-steps aim at pushing her to come up to their specific expectations.

Contrariwise, being a member of foresight core-team, she has to answer needs of all stakeholders and to support the 
realization of project-goals set by the Austrian funding-agency. This multi-functional role demands high role-flexibility and huge clarification-efforts in the core-team in order to allow the application of a neutral transformation-room for mutual learning.

As the residential housing community has developed specific values and communication-patterns over time the project-team from the very beginning faced an intensive cohesion critically questioning stakeholders and projectmembers coming from outside. Translating and interlinking foresight-terms and methods to given needs was essential for carefully and steadily built-up trust for the steering committee as well as inhabitants concerned. But it was only after the steering-group members were able to shape foresight-methods and stakeholders transformed best- and worst-case scenarios in impressive play-back scenes (sketches) the cohesion of the overall stakeholder group and satisfaction of Sargfabrik members emerged. Inhabitants demand a continuous stage allowing performing their beliefs and insights. This forces the project-team to find a suitable way to allow analysis and results on base of a highly innovative method-mix. Without touching hearts and opening desires, project members had no chance to get in touch with the citizens initiating dealing with new-information and allowing group-cohesion including also "strangers" from outside.

Challenges for the project-team were to a) guarantee outside-perspectives and information complementary to a self-contained residential home-culture, b) buildup a trustful relationship remaining in parallel distinct beyond assimilation, c) appreciate and meet the needs of all stakeholders in an equidistant-mode. Besides the CitizenForesight had to d) offer free-space for inspiring, mutual learning and to e) support decision-making for a follow-up project.

\section{Selection-criteria for a context-sensitive method-mix}

Selection-criteria for both Citizen-Foresight cases reflect challenges of their contexts. The following comparison 
of both Citizen-Foresights shows that dislodged contexts and the inclusion of mayors (WEGE-2025) demand huge coordination efforts and self-reflexivity of project teams. On the demand-side, we see citizens prefer inspiring, interactive methods while mayors often call for external expertise. Thus Citizen-Foresights including politicians and citizens require balancing expert-driven (top-down) and creativity-driven methods (bottom-up) in an equivalent way. While mayors claim responsibility for decision-making, decision-making of the residential house remains in the hand of inhabitants concerned.

Stakeholder-forums including self-organized communities often suffer from a lack of outside perspectives. This requires widening the variety of stakeholder-groups and adding advisory-boards counterbalancing internal-driven steering-boards. As self-organized communities are both, end-users and decision-makers, there is no specific demand for external expertise aiming at legitimating. In contrast to policy-foresights, mutual learning and fun are utmost for dealing with unfamiliar terms and information. Enhancing deepening the relationship between residential housing members and lifting tacit knowledge available serves as a central precondition to offer outside perspectives and initiate learning inside out.

Table 1

Selection-criteria | method-mix | Citizen-Foresights

\begin{tabular}{|c|c|}
\hline WEGE-2025 "Mühlviertel" & $\begin{array}{l}\text { SAIL-Vienna } 2035 \\
\text { "Sargfabrik" }\end{array}$ \\
\hline $\begin{array}{l}\text { 1. Criterion: previous initia- } \\
\text { tives } \\
\text { Methods: project-team: } \\
\text { interviews, searchers, litera- } \\
\text { ture-reviews; expert-panels; } \\
\text { Architecture: Local project- } \\
\text { team }\end{array}$ & $\begin{array}{l}\text { 2. Criterion: outside-perspec- } \\
\text { tive } \\
\text { Methods: advisory-board } \\
\text { \& steering-board: steer- } \\
\text { ing-board members learning } \\
\text { from advisors; project-team; } \\
\text { inputs, analytical methods; } \\
\text { Stakeholder-forums: stak- } \\
\text { holder-mix }\end{array}$ \\
\hline$\rightarrow$ Expertise | Evidence & $\rightarrow$ Expertise | Interaction \\
\hline
\end{tabular}




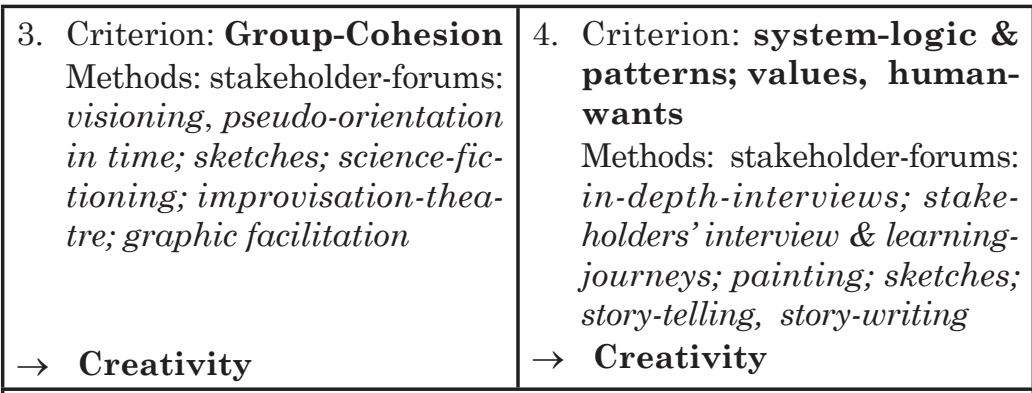

5. Criterion: Common-ground mayors \& citizens | WEGE2025

Methods: steering-board: assessment of intermediate results stakeholder-forums: sense-making \& sounding-role of mayors; moderation of break-out-groups

$\rightarrow$ Interaction

6. Criterion: Mutual-learning | WEGE-2025

Methods: project-team: cultural-islands; stakeholder-forums: implementation of trust \& appreciation; co-creation; designthinking approach; scale-parties; World-Café; delegation conference; key-technologies; result-gallery; collaborative mapping; ethnological learning-journeys, etc.

$\rightarrow$ Creativity | Interaction

7. Criterion: Having Fun | SAIL-Vienna 2035

Methods: See Criteria "mutual learning" \& "group-cohesion" $\rightarrow$ Creativity | Interaction

8. Criterion: Formal-results Methods | WEGE-2025

steering-board-WS: assessment of results; stakeholder-forums: environmental-analysis; story-lines; scenario-building; roadmapping; action-plans; reports; final conference;

$\rightarrow$ Expertise

9. Criterion: decision-making 10. Criterion: decision-making of mayors;

Methods: steering-board-WS of the system-as-a-whole; Methods: social-architecture; stakeholder-forums: see criteria Group-cohesion; mutual learning; having fun;

\begin{tabular}{|c|c|}
\hline$\rightarrow$ Interaction & $\rightarrow$ Creativity | Interac \\
\hline Main focus of methods & Main focus of methods \\
\hline $\begin{array}{l}\rightarrow \text { Interaction } 3 \mathrm{x} \\
\rightarrow \text { Expertise } 2 \mathrm{x} \\
\rightarrow \text { Creativity } 2 \mathrm{x}\end{array}$ & $\begin{array}{l}\rightarrow \text { Interaction } 3 \mathrm{x} \\
\rightarrow \text { Creativity } 3 \mathrm{x} \\
\rightarrow \text { Expertise } 1 \mathrm{x}\end{array}$ \\
\hline
\end{tabular}


Summing up we see that Citizen-Foresights have a primary focus on interaction and creativity. Citizen-Foresights including policy-makers require more external expertise and analytical methods whereas mainly citizen-driven foresights do not work without carefully building-up trust and allowing citizens to show their claims and capabilities. Referring to experiences related to Policy-Foresights e.g. FreightvisionEurope (Helmreich et al., 2011; Wilhelmer, 2013), FV-Austria (Wilhelmer, 2013) we see that Policy-Foresights primarily apply expert and evidence-driven methods, completed by interactive set-ups. Creative methods within these application fields are only on rare occasions.

\section{Condusion: societal transformation in need of hybrid co-creation set-ups}

Our overall conclusion is that coordination of diverse organizations, as part of governance of societal change needs reflexive system learning.

Due to the circumstance that dealing with complex societal transformation demands comprehensive efforts of a wide range of organizations, we claim that new, hybrid formats like Participatory and Citizen-Foresights, living-labs, or city-labs interlinking diverse stakeholders in co-creation are strongly needed.

Applied research should go on implementing and evaluating the transformative effect of these hybrids. This will allow an important step forward to implementing various innovative formats for coordinating societal transformation in European practice.

\section{References}

Biegelbauer, P. (2013). Wie lernt die Politik - Lernen aus Erfahrung in Politik und Verwaltung. Wiesbaden: Verlag für Sozialwissenschaften.

Boden, M., Cagnin, C., Carabias, V., Haegeman, K. and Konnola, T. (2010). Facing the future: time for the EU to meet global challenges, EUR 24364 EN. Luxembourg: Publications Office of the European Union. 
Cagnin, C., Keenan, M., Johnston, R., Scapolo, F., Barré, R., (Eds.) (2008). Future-Oriented Technology Analysis -Strategic Intelligence for an Innovative Economy. Heidelberg: Springer Verlag.

Cagnin, C., Amanatidou, E., Keenan, M. (2012). Orienting European innovation systems towards grand-challenges and the roles that FTA can play. Science and Public Policy, 39(2), 140-152. doi:10.1093/scipol/scs014

Erickson, M. H. (1954). Pseudo-orientation in time as an hypnotherapeutic procedure. International Journal of Clinical and Experimental Hypnosis, 2(4), 261-283.

Freeman, C., Soete, L. (1997). The Economics of Industrial Innovation. London: Pinter.

Georghiou, L., Cassingena Harper, J., Keenan, M., Miles, I., Popper, R. (2008). The Handbook of Technology Foresight: Concepts and Practice. Northampton, MA: Edward Elgar Publishing.

Helmreich, S., Düh, J., Kubeczko, K., Wilhelmer, D. (2011). Foresight Process. In: S. Helmreich, H. Keller (Eds.), FREIGHTVISION - Sustainable European Freight Transport 2050. Forecast, Vision \& Policy Recommendation. Berlin-Heidelberg: Springer Verlag.

Hüther, G. (2010). Die Macht der inneren Bilder. Wie Visionen das Gehirn, den Menschen und die Welt verändern. Göttingen: Vandenhoeck \& Ruprecht Verlag.

Laegreid, P., Sarapuu, K., Rykkja, L. H., Randma-Liiv, T. (2015). New coordination challenges in the welfare state. Public-Management-Review, 17(7), 927-939.

Lindner, R. (2012). Cross-Sectoral Coordination of STI-Policies: governance principles to bridge policy-fragmentation. In: Innovation System Revisited: experiences from 40 years of Fraunhofer ISI Research (pp. 275-289). Stuttgart: Fraunhofer Verlag.

Markowitsch, H. J. (2013). A paradigm shift is needed! In: M. Eckoldt, Can the brain understand the brain? Dialogues about brain-research and the limits of perception and insights (pp. 25-28). Heidelberg: Carl-Auer Verlag.

Miles, I. (2008). Foresight Methodology. In: L. Georghiou, J. C. Harper, M. Keenan, I. Miles., R. Popper (Eds.), The Handbook of Technology Foresight: Concepts and Practice. Northampton, MA: Edward Elgar Publishing.

Nowotny, H., Scott, P., Gibbons, M. (2003). "Mode 2" revisited: The new production of knowledge. Minerva, 41(3), 179-194.

Peters, B. G. (1998). Managing Horizontal Government: The Politics of Co-Ordination. Public administration, 76(2), 295-311.

Popper, R. (2008). How are foresight methods selected? Foresight, 10(6), 62-89.

Rittel, H., Weber, M. (1973). Dilemmas in a general theory of planning. Policy Sciences, 4(2), 155-69. 
Schein, E. H. (2010). Organizational-Culture and Leadership. San Francisco: Jossey-Bass.

Schmidt, G. (2004). Love affairs betwixt problems and solutions. Hypnosystemic work in difficult contexts. Heidelberg: Carl-Auer Verlag.

Senge, P. M. et al. (2011). The necessary revolution. How people and organizations cooperate aiming at co-creation of a sustainable world. Heidelberg: Carl-Auer Verlag.

Verhoest, K., G. Bouckaert, et al. (2007). Janus-faced reorganization: Specialization and coordination in four OECD countries in the period 1980-2005. International Review of Administrative Sciences, 73(3), 325-348.

Wilhelmer, D. (2009). Reminiscence of a better future. Syntax for a complementary innovation counselling. Heidelberg: Carl-Auer Verlag.

Wilhelmer, D., Nagel, R. (2013). FORESIGHT. Ein Managementhandbuch für das Gestalten von Open Innovation. Heidelberg: Carl-Auer Verlag.

Wilhelmer, D. (2013). Zukunft entsteht in Co-Kreation. Change $X, 12.12 .2013$.

Willke, H. (1998). Systemisches Wissensmanagement. Stuttgart: Lucius \& Lucius.

Willke, H. (2004): Einführung in das systemische Wissensmanagement. Heidelberg: Carl-Auer Verlag. 
